\title{
EPIDEMIOLOGICAL PROFILE OF BREAST CANCER MORTALITY IN GOIÁS FROM 2010 TO 2019
}

Amanda Munik de Freitas Barbosa', Alexia Jesus Araujo², Fabrícia de Azevedo Alves³, Sarah Carvalho Talone³, Vanessa Leal Vitória ${ }^{3}$, Valdirene Fernandes Moreira³, Andrea Alves Ribeiro³

${ }^{1}$ Faculdades Fan Padrão - Goiânia (GO), Brazil.

²Universidade Federal de Jataí - Jataí (GO), Brazil.

3Pontifícia Universidade Católica de Goiás - Goiânia (GO), Brazil.

Objective: To describe the mortality profile for breast cancer in Goiás from 2010 to 2019. Methods: This is a quantitative cross-sectional descriptive study using data from the Mortality Information System. The profile was evaluated for sex, age, and year of death. Results: In all, 4,267 deaths occurred in the state, mainly in the municipalities of Goiânia (32.68\%), Aparecida de Goiânia (7.92\%), and Anapolis (6.79\%). The female sex accounted for $98.85 \%$ of the deaths and the male for $1.15 \%$. As for age, the lowest percentage is between the ages of 13 and 19, while the highest is of 50 and 59 , with $26.29 \%$ of the relative frequency of deaths decays. Conclusion: Incentives for health promotion, prevention, surveillance, and increased coverage of mammograms in the state of Goiás can assist in the reduction of deaths from breast cancer in the state.

Keywords: Breast Neoplasms; Health Profile; Mortality; Risk Factors. 